\title{
COMPUTER ASSISTED HUMAN KARYOTYPING - AN ANALYSIS OF 131 CASES
}

\author{
Rahman $M^{1}{ }^{1}$, Giti $S^{2}$, Islam $\mathrm{MS}^{3}$, Shaha $\mathrm{D}^{4}$, Yousuf $\mathrm{AKMA}^{5}$, Bhuyain $\mathrm{MN}^{6}$, Khatun $\mathrm{N}^{7}$, Kawsar $\mathrm{NM}^{8}$
}

\begin{abstract}
Introduction: Karyotyping is the process of pairing and ordering all the chromosomes of an organism, thus providing a genome-wide snapshot of an individual's chromosome. G-banded karyograms are routinely used to diagnose a wide range of chromosomal abnormalities in individuals. Although the resolution of chromosomal changes detectable by G-banded karyotyping is typically a few megabases, this can be sufficient to diagnose certain categories of abnormalities.
\end{abstract}

Objectives: The primary aim of this study was to investigate the different types of chromosomal aberrations and their relative frequencies in a group of referred patients with suspected genetic disorders.

Methods: This observational study was carried out at Armed Forces Institute of Pathology (AFIP) for a period of two years from January 2011 to December 2012. A total of 131 patients were included in this study. These patients were referred to AFIP from different Combined Military Hospitals $(\mathrm{CMH})$ of Bangladesh Army and also from civil medical installations. All the patients were subjected to full genetic study; complete genetic examination and pedigree construction was done to exclude nonchromosomal causes of anomaly. Detailed history and physical findings were also noted in a prescribed format. The study included peripheral lymphocyte culture by a standard method using the $\mathrm{G}-$ banding technique.
Results: Out of 131 patients, $54(42.2 \%)$ were male and $77(57.8 \%)$ were female with male to female ratio $0.7: 1$. The age limit of the patient ranges from 04 days to 70 years. Most of the patients $(32.1 \%)$ were in the age group of $0-10$ years followed by $21-30$ year age group $(30.5 \%)$. Consanguineous marriage was found in 15 (11.5\%) cases in which $3(2.3 \%)$ cases had chromosomal aberrations. Recurrent abortion was the main clinical indication (18.3\%) followed by infertility (15.3\%). Chromosomal aberrations were detected in 26 patients $(19.8 \%)$; of these, $20(15.2 \%)$ involved autosomes, while only $6(4.6 \%)$ involved gonosomes. Trisomy 21 was detected in 12 (9.1\%) patients and Philadelphia chromosome was found in $8(6.1 \%)$ patients. Turner syndrome was detected in $5(3.8 \%)$ patients and Klinefelter syndrome was found in $1(0.8 \%)$ patient.

Conclusion: The precise delineation of different types of chromosomal aberrations is only possible using clinical examination and advanced cytogenetic tools by experienced cytogeneticists.

Key-words: G-banded karyotyping, Chromosomal aberrations, Recurrent abortion, Infertility, Trisomy 21, Philadelphia chromosome, Turner syndrome, Klinefelter syndrome.

1. Lt Col Md Mizanur Rahman, MBBS, MCPS, DCP, FCPS, Classified Spl in Pathology, AFIP, Dhaka;

2. Col Susane Giti, MBBS, MCPS, FCPS, Classified Spl in Pathology, AFIP, Dhaka; 3. Maj Gen Md Saiful Islam, MBBS, MCPS, FCPS, Ex Commandant and Classified Spl in Pathology, AFIP, Dhaka; 4. Maj Gen Debashish Shaha, MBBS, FCPS, Commandant, AFIP, Dhaka; 5. Col A K M Abu Yousuf, MBBS, FCPS, Classified Spl in Pathology, $\mathrm{CMH}$, Jessore; 6. Maj Mohammad Nuruzaman Bhuyain, MBBS, MCPS, DCP, Graded Spl in Pathology, AFMI, Dhaka; 7. Dr. Nasima Khatun, MBBS, MPH(RCH), Medical Consultant, Shahriar (Gildan) Fabric Industry Limited, Ashulia, Savar; 8. Lt Col Narjis Maliha Kawsar, MBBS, DCP, FCPS, Assoc Prof of Microbiology, AFMC, Dhaka. 


\section{Introduction}

To date, around 20000 chromosomal abnormalities have been registered on laboratory data bases. While on individual basis most of these are very rare, together they make a major contribution to human morbidity and mortality. Chromosome abnormalities account for a large proportion of spontaneous pregnancy loss and childhood disability, and also contribute to the genesis of a significant proportion of malignancy in both childhood and adult life as a consequence of acquired somatic chromosome aberrations ${ }^{1}$.

Chromosome abnormalities are present in at least $10 \%$ of all spermatozoa and $25 \%$ of mature oocytes ${ }^{1}$. Between $15 \%$ and $20 \%$ of all recognized pregnancies end in spontaneous miscarriage, and many more zygotes and embryos are so abnormal that survival beyond the few days or weeks after fertilization is not possible. Approximately $50 \%$ of all spontaneous miscarriages have a chromosome abnormality and the incidence of chromosomal abnormalities in morphologically normal embryos is around $20 \%$. These observations indicate that chromosome abnormalities account for the loss of a very high proportion of all human conceptions. From conception onwards the incidence of chromosome abnormalities falls rapidly. By birth it has declined to a level of $0.5-1 \%$, although the total number is much higher $(5 \%)$ in stillborn infants ${ }^{1}$.

The impact of chromosomal abnormalities is greatest during foetal life when they have their highest frequency and represent a major cause of fetal loss $^{2}$. The frequency of chromosomal abnormalities is quite different in neonates $(0.7 \%)$ as compared to abortuses (about $50 \%$ ), some aneuploidies are lethal in utero ${ }^{3}$. The major autosomal abnormalities share a number of phenotypic features that are not distinctive or specific, including mental retardation, cardiac malformation and growth deficiency. While there is variability within every cytogenetic syndrome, neonatal death and serious congenital malformations are frequent manifestations. Most of the specific cytogenetic syndromes have a constellation of features that distinguish them and allow the clinician to suspect the condition ${ }^{2}$.
Karyotyping is the process of pairing and ordering all the chromosomes of an organism, thus providing a genome-wide snapshot of an individual's chromosome. Karyotypes are prepared using standardized staining procedures that reveal characteristic structural features for each chromosome. Clinical cytogeneticists analyze human karyotypes to detect gross genetic changes- anomalies involving several megabases or more of DNA. Karyotypes can reveal changes in chromosome number associated with aneuploid conditions, such as trisomy 21 (Down syndrome). Careful analysis of karyotypes can also reveal more subtle structural changes, such as chromosomal deletions, duplications, translocations or inversions. In fact, karyotypes are becoming a source of diagnostic information for specific birth defects, genetic disorders and even cancer ${ }^{4}$. Today, G-banded karyograms are routinely used to diagnose a wide range of chromosomal abnormalities in individuals. Although the resolution of chromosomal changes detectable by G-banded karyotyping is typically a few megabases, this can be sufficient to diagnose certain categories of abnormalities ${ }^{5}$. The primary aim of this study was to investigate the different types of chromosomal aberrations and their relative frequencies in a group of patients with suspected genetic disorders and to identify precisely the role of cytogenetic investigation in confirming the diagnosis.

\section{Materials and Methods}

This study was conducted at Armed Forces Institute of Pathology (AFIP) for a period of two years from January 2011 to December 2012. A total of 131 patients were included in this study. These patients were referred to AFIP from different Combined Military Hospitals (CMH) of Bangladesh Army and also from civil medical installations. All the patients were subjected to full genetic study; complete genetic examination and pedigree construction was done to exclude nonchromosomal causes of anomaly. Detailed history and physical findings were also noted in a prescribed format. The study included peripheral lymphocyte culture by a standard method using the G-banding technique according to Seabright ${ }^{6}$. 
The protocol for the preparation of the chromosomes for karyotyping was as follows: About $2 \mathrm{ml}$ of heparinized blood was collected in evacuated test tube from peripheral veins of the referral patients. Lymphocytes were grown in PB Max karyotyping media containing antibiotics (penicillin/ streptomycin) and 15\% serum supplementation. Phytohaemagglutinin (PHA) was added as a mitotic stimulant $(0.5 \mathrm{ml}$ of the inoculum) and the samples were incubated for 72 hours at $37^{\circ} \mathrm{C}$ incubator. The cells were arrested at metaphase with $0.1 \%$ colchicine; chromosome elongation was accomplished by adding $1 \%$ ethydium. Hypotonic treatment was done with $\mathrm{KCL}$ solution and cells were fixed with 3 changes of fixative (3:1, methanol: glacial acetic acid). The prepared slides were stained with GTG (G-bands using Trypsin and Geimsa stain). Chromosome analysis was done under $100 \mathrm{x}$, magnification ${ }^{7}$. At least 30 metaphase spreads were screened for each patient and 5 metaphases were captured using a CCD (Charge Coupled Device) camera. The captured picture was further enhanced by adjusting the sharpness, brightness and contrast and the printout was taken ${ }^{8}$.

\section{Results}

A total of 131 patients' karyotyping was analyzed in this study. Out of them, $54(42.2 \%)$ were male and $77(57.8 \%)$ were female with male to female ratio $0.7: 1$. The age limit of the patient ranges from 04 days to 70 years. Most of the patients $(32.1 \%)$ were in the age group of $0-10$ years followed by 21-30 year age group (30.5\%) (Table-I).

Table-I: Age distribution of the patients $(n=131)$.

\begin{tabular}{|c|c|c|}
\hline Age (yrs.) & Frequency & Percentage (\%) \\
\hline $0-10$ & 42 & 32.1 \\
\hline $11-20$ & 30 & 22.9 \\
\hline $21-30$ & 40 & 30.5 \\
\hline $31-40$ & 14 & 10.7 \\
\hline $41-50$ & 02 & 1.5 \\
\hline $51-60$ & 01 & 0.8 \\
\hline $61-70$ & 02 & 1.5 \\
\hline Total & $\mathbf{1 3 1}$ & $\mathbf{1 0 0}$ \\
\hline
\end{tabular}

The clinical indication of karyotyping is shown in Table-II. Recurrent abortion was the main clinical indication (18.3\%) followed by infertility (15.3\%).
Table-Il: Clinical indications of cases referred for karyotyping $(\mathrm{n}=131)$.

\begin{tabular}{|l|c|c|}
\hline Clinical indication & Frequency & Percentage (\%) \\
\hline Recurrent abortion & 24 & 18.3 \\
\hline Infertility & 20 & 15.3 \\
\hline Congenital malformation & 15 & 11.5 \\
\hline Developmental delay & 13 & 9.9 \\
\hline Growth retardation & 09 & 6.9 \\
\hline Short stature & 08 & 6.1 \\
\hline CML & 08 & 6.1 \\
\hline Delayed puberty & 07 & 5.3 \\
\hline Mental retardation & 07 & 5.3 \\
\hline Secondary infertility & 06 & 4.6 \\
\hline Abnormal/Ambiguous genitalia & 04 & 3.1 \\
\hline Gynaecomastia & 03 & 2.3 \\
\hline Protruded tongue & 02 & 1.5 \\
\hline Neonatal jaundice & 02 & 1.5 \\
\hline Parents of Down's baby & 02 & 1.5 \\
\hline Tall stature & 01 & 0.8 \\
\hline Total & 131 & 100 \\
\hline
\end{tabular}

Out of 131 patients on whom chromosomal analysis was done, normal karyotyping was found in 105 patients $(80.15 \%)$ and chromosomal aberrations were detected in 26 patients (19.85\%). Among 26 patients of chromosomal aberrations 20 $(76.92 \%)$ involved autosomes, while only 6 (23.08\%) involved gonosomes (Table-III).

Table-III: Distribution of chromosomal aberrations $(n=26)$

\begin{tabular}{|l|c|c|}
\hline Type of Chromosomes involved & Frequency & Percentage (\%) \\
\hline Autosomes & 20 & 76.92 \\
\hline Gonosomes & 06 & 23.08 \\
\hline
\end{tabular}

Among autosomal aberrations, trisomy 21 was detected in $12(60.0 \%)$ patients and Philadelphia chromosome was found in $8(40.0 \%)$ patients. Among trisomy 21, 7 (58.3\%) patients had classic trisomy 21 and 5 (41.7\%) patients had mosaic trisomy 21 (Table-IV).

Table-IV: Distribution of autosomal aberrations $(n=20)$

\begin{tabular}{|c|c|c|}
\hline Autosomal chromosome aberrations & Frequency & Percentage $(\%)$ \\
\hline Thisomy 21 & 12 & 60.0 \\
\hline Classictrisomy 21 $(47, X X+21=03 ; 4$ & 7 & 58.3 \\
\hline Mosaictrisomy $21(46, X X 147, X X+21=2 ; 46, X Y \mid 47, X Y+21=31$ & 5 & 41.7 \\
\hline Philadelphia chromosome & 8 & 40.0 \\
\hline
\end{tabular}


Among gonosomal aberrations, Turner's syndrome was detected in $5(83.3 \%)$ patients and Klinefelter syndrome was found in $1(16.7 \%)$ patients. Two patients $(40.0 \%)$ had classic Turner syndrome and $03(60.0 \%)$ patients had mosaic Turner syndrome (Table-V).

Table-V: Chromosomal aberrations involving onosomes $(\mathrm{n}=6)$

\begin{tabular}{|c|c|c|}
\hline Gonosomal aberrations & Frequency & Percentage (\%) \\
\hline Turner syndrome & 5 & 83.3 \\
\hline $\begin{array}{l}\text { Classic Turner syndrome }(45, X) \\
\text { Mosaic Turner syndrome }(45, X 146, X X)\end{array}$ & $\begin{array}{l}2 \\
3\end{array}$ & $\begin{array}{l}40.0 \\
60.0\end{array}$ \\
\hline Klinefelter syndrome (47, XXY) & 1 & 16.7 \\
\hline
\end{tabular}

In this study, consanguineous marriage was found in $15(11.5 \%)$ cases in which $3(20 \%)$ cases had chromosomal aberrations (Table-VI).

Table-VI: Correlation between consanguineous marriage and chromosomal aberrations.

\begin{tabular}{|c|c|c|}
\hline Traits & Frequency & Percentage (\%) \\
\hline $\begin{array}{c}\text { Consanguineous marriage } \\
(n=131)\end{array}$ & 15 & 11.5 \\
\hline $\begin{array}{c}\text { Chromosomal aberrations } \\
\text { (Down syndrome, } n=15)\end{array}$ & 3 & 20.0 \\
\hline
\end{tabular}

\section{Discussion}

In this study, out of 131 patients' chromosomal aberrations were found in $19.85 \%$ cases. There are wide variations in the frequency of chromosomal aberrations in individuals suspected of having genetic disorders ${ }^{9,10}$. Berry et al. studied 114 patients and found chromosomal aberrations in $18(15.8 \%)^{11}$. Navsaria et al. evaluated 1000 patients and found chromosomal aberrations in $160(16 \%)^{12}$. Al-Awadi et al. studied 472 patients and found 92 cases $(19.5 \%)^{13}$. Al-Arrayed reported a frequency of $27 \%$ among 500 patients $^{14}$. Verma and Dosik found a frequency of $27.1 \%$ among 357 patients ${ }^{15}$ and Singh reported a frequency of $28.8 \%$ among 451 patients $^{16}$. Incidence of chromosomal aberrations in this study correlates with different studies. In consecutive neonatal studies, autosomal abnormalities are usually as common as sex chromosome aberrations ${ }^{17}$. In studies based on a referred population with phenotypic abnormalities, such as the present study, autosomal abnormalities $(76.92 \%)$ are much higher than those of the gonosomes $(23.08 \%)$. This figure correlates with other studies $^{18,19}$. This is mainly due to the fact that sex chromosome imbalance has a much less deleterious effect on the phenotype than does autosomal aneuploidy ${ }^{20}$.

Trisomy 21 has been recognized for more than 100 years. Because it is a common and familiar disorder. Down syndrome has been studied much more thoroughly than other chromosomal disorders. The Down syndrome phenotype is due to triple amount of chromosome ${ }^{21}$. The frequency of Down syndrome in patients with abnormal chromosomes in the present study is $60 \%$. This value was lower than other surveys ${ }^{13,19,21}$. This could be attributed to the karyotyping of only referred cases. The frequency of classic trisomy 21 amongst Down syndrome in this study was $58.3 \%$. This value differs from other studies which ranged from $84.6 \%$ to $90 \%{ }^{17}$. This difference could be due to low sample size and analysis of only referred cases. The incidence of mosaicism in Down syndrome patients in the present study is $41.7 \%$ which is much higher than reported range between $0 \%$ and $4 \%$. This could be due to fact that actual level depends on the maternal age distribution and the rate of indication for prenatal diagnosis. In this study, Philadelphia chromosome was found in 8 diagnosed cases $(40 \%)$ of chronic myeloid leukaemia among 20 autosomal chromosomal aberrations. Philadelphia chromosome was found in all referred cases of chronic myeloid leukaemia. This is due to high incidence of Philadelphia chromosome in chronic myeloid leukaemia. The incidence of Turner syndrome in consecutive neonates has been reported to be $0.04 \%{ }^{22}$. Turner syndrome is one of the few chromosomal aberrations that can be recognized clinically during infancy or childhood based on short stature, broad shield chest, lymphedema of the lower limbs, webbed neck and multiple minor anomalies ${ }^{22}$. However, karyotyping is necessary to confirm the diagnosis. The present study included five $(3.8 \%)$ patients with Turner syndrome. Their chromosomal patterns were variable: $45, X$ (two cases) and 45, X/46, XX (three cases). This frequency was more or less similar to Kenue et $\mathrm{al}^{19}$ but it was lower than that reported by Guera et $\mathrm{al}^{23}$. 
In this study, consanguineous marriage was found in $15(11.5 \%)$ cases in which $3(20 \%)$ cases had Down syndrome. Down syndrome does not show any increase in the frequency of consanguineous marriages among their parents with respect to the general population, and therefore does not support the hypothesis of an autosomal gene controlling mitotic nondisjunction. Many studies do not show any increase in the frequency of consanguineous marriages even among paternal and maternal grandparents of the affected children, thus not supporting the other possible explanation of an autosomal recesive condition in one of the patient's parent's which would cause meiotic nondisjunction ${ }^{24}$. The findings in this study may be incidental.

\section{Conclusion}

Among the referred cases with suspected genetic disorders having phenotypic abnormalities, the frequency of autosomal chromosomal aberrations was found to be much higher than sex chromosome abnormalities. Trisomy 21 was the most frequent followed by Philadelphia chromosome.The precise delineation of different types of chromosomal aberrations is only possible using clinical examination and advanced cytogenetic tools by experienced cytogeneticists. Recognition of parents with chromosomal abnormalities is also important as the risk of recurrence is high in some cases. This cytogenetic knowledge allows proper genetic counseling to be provided.

\section{References}

1. Muller RF, Young ID. Chromosome disorders. In: Turnpenny PD, Ellard S, eds. Emery's elements of medical genetics, Edingburg, Churchill Livingstone, 2007. 261-81.

2. Seashore MR, Wappner RS. Review of fundamental genetics. In: Seashore MR, ed. Genetics in primary care and clinical medicine. United States of America. Prince-Hall International Inc., 1996: 12-9.

3. Thompson JS, Mclnness RR, Wilard HF. Genetics in medicine. London, WB Saunders Company, 1991: 201-28.
4. Connor CO. Karyotyping for chromosomal abnormalities. Nature education, 2008, 1.

5. Caspersson T, Zech L, Johansson J. Differential banding of alkylating fluorochromes in human chromosomes. Experimental Cell Research 60, 1970: $315-9$.

6. Seabright M. A rapid banding technique for human chromosomes. Lancet, 1971; 2: 971-2.

7. Rajangam S, Tilak $\mathrm{P}$, Aruna N, Devi R. Karyotyping and counselling in bad obstetric history and infertility. Iranian Journal of Reproductive Medicine, 2007; 5 (1): 7-12.

8. Kingston $\mathrm{MH}$. Chromosome analysis. In: Kingston $\mathrm{MH}$, ed. ABC of clinical genetics. London, BMJ Publishing group, 1994: 21-5.

9. Shah V, Krisna DS, Murthy SK. Cytogenetic studies in a population suspected to have chromosomal abnormalities. Indian Journal of Paediatrics, 1990; 57: 235-43.

10. Nkanza NK, Tobani CT. Chromosomal abnormalities. Experiences in Harare Hospital. East African Medical Journal, 1991; 7: 87-8.

11. Berry R. Benefit of repeat cytogenetic studies in a high-risk paediatric population. American journal of human genetics, 1991; 49 (4): 257.

12. Navsaria D. Chromosomal anomalies in 1000 children referred with suspected genetic disorders. Human heredity, 1993; 43 (3): 137-40.

13. Al - Awadi SA. Reestablishment of genetic services in Kuwait. American journal human genetics, 1992; 51(4): 416.

14. Al-Arrayed SS. Chromosomal abnormality in Bahrain (6 year study). American journal of human genetics, 1991; 49 (4): 255.

15. Verma RS, Dosik $H$. Incidence of major chromosomal abnormalities in a referred population of suspected chromosomal aberrations: a report of 537 cases. Clinical genetics, 1980; 17: 305-8. 
16. Singh DS. Cytogenetic study of individuals suspected of chromosome anomalies. Clinical pediatrics, 1977; 16: 619-22.

17. Gardner RJ, Sutherland GR. Elements of medical cytogenetics. In: Gardner RJ, Sutherland GR, eds. Chromosomal abnormalities and genetic counselling. Oxford. Oxford University Press, 1996: 6-9.

18. Al-Awadi SA. A five year experience with autosomal abnormalities in Kuwait. Journal of the Kuwait Medical Association, 1985; 19: 269-75.

19. Kenue RK. Cytogenetic analysis of children suspected of chromosomal abnormalities. Journal of Tropical Paediatrics, 1995; 41: 77-80.

20. Mutton D, Alberman E, Hook EB. Cytogenetic and epidemiological findings in Down syndrome, England and Wales 1989 to 1993. Journal of medical genetics, 1996; 33: 387-94.
21. Mokhtar MM. Chromosomal aberrations in children with suspected genetic disorders. Eastern Mediterranean Health Journal, 1997; 3(1): 114-22.

22. Ikeda Y. An anthropometric study girl with Ulrich Turner syndrome. American journal of human genetics, 1982; 12: 271-80.

23. Guera VR. Fifteen years of cytogenetics in the Dominican Republic. American journal of human genetics, 1991; 41: 256.

24. Devoto M, Prosperi L, Bricarelli FD, Coviello DA, Croci G, Zelante L, Ferranti G, et al. Frequency of consanguineous marriage among parents and grandparents of Down patients. Hum Genet. 1985; 70(3):256-8. 